\title{
Mechanisms of Formation of Submicron Grain Structures by Severe Deformation
}

\author{
P.B. Prangnell ${ }^{1, a}$, Y. Huang ${ }^{1, b}$, M. Berta ${ }^{1}$ and P.J. Apps ${ }^{2 c}$ \\ ${ }^{1}$ Materials Science Centre, School of Materials, University of Manchester/UMIST, Grosvenor \\ Street, Manchester, M1 7HS, UK \\ ${ }^{2}$ Now at the Health and Safety Laboratory, Broad Lane, Sheffield, S3 7HQ, UK \\ aphilip.prangnell@manchester.ac.uk, 'Yan.Huang2@manchester.ac.uk, 'pete.apps@hsl.gov.uk
}

Keywords: Severe deformation, ultrafine grains, ECAE, grain subdivision, deformation bands

\begin{abstract}
The grain refinement mechanisms operating during severe deformation processes, like ECAE, are discussed using data obtained from model Al-alloys. Refinement occurs predominantly by orientation splitting, micro and macroshear banding, and the geometric requirement for high angle boundary area to increase with strain. The deformation structure evolution is affected strongly by the processing route, die geometry, and material parameters. Both cell bands and microshear bands show strong alignment with the dies shear plane. Shear bands are promoted by changes in the shear plane orientation each extrusion cycle. At high strains a steady state is approached, where the grain size converges with the subgrain size, controlled by dynamic boundary migration.
\end{abstract}

\section{Introduction}

The last decade has seen a dramatic rise in interest in the use of severe deformation techniques to produce ultra fine-grained materials. The potential benefits of submicron-grained aluminium alloys, such as enhanced strength and superplasticity, are well-documented [1], but are offset by some negative properties, such as a tendency for low stable elongation and shear localization [2]. Several processing methods have been shown to be effective for the production of ultra-fine grained metals, including; Equal Channel Angular Pressing/Extrusion (ECAP/E) and Accumulative Roll Bonding (ARB) [3]. More recently, continuous variants of the ECAE process have been developed, which in the future will allow more commercially viable production [4]. All of these techniques involve deformation to ultra-high plastic strains (typically $\varepsilon_{\mathrm{vm}}=6-10$ ) without a net billet shape change, which would otherwise result in a foil or filament. This is achieved using combinations of shear strains, redundant deformation, and physical intervention. The deformation history in such processes is frequently complex, sensitive to the tooling and friction conditions and does not generally involve a constant strain path. This is especially true for the ECAE/P process (e.g [5-7]).

Previously a 'true' submicron grained material, produced by a deformation process, has been defined as requiring the average spacing of high angle boundaries ( $\mathrm{HABs}$ ), misorientated by $>15^{\circ}$, to be less than $1 \mu \mathrm{m}$ in all directions and the fraction of $\mathrm{HAB}$ area to be greater than $70 \%$ [8]. This definition was originally proposed as in many cases materials deformed by severe deformation techniques are simply called submicron grained, based on measurement of their cell size in the TEM, without discriminating between high and low angle boundaries. Understanding how deformation structures evolve to ultra-high strains and the grain refinement mechanisms involved is thus of considerable interest not least because, as will be seen with certain material and deformation route combinations, ultra-fine grained materials, according to the above definition, are not obtained and the materials produced still predominantly contain subgrains [9]. 
The general behaviour of the deformation structure evolution using the ECAE process has been previously reported, particularly using route $\mathrm{A}$ (no billet rotation) $[8,10]$. The increase in $\mathrm{HAB}$ area with strain originates from grain subdivision processes, such as deformation banding via orientation splitting and micro-shearbanding (which predominantly occurs at low stains $<3$ ), and the extension of grain boundary area with strain. The importance of orientation splitting and shear banding has been noted by other researchers $[5,11]$. With deformation processes involving continuous material element distortion, (e.g. ECAE -Route A) the HABs rotate and compress in spacing with strain to form a lamellar structure. The spacing of the lamellar boundaries reduces until it converges with the subgrain size forming thin ribbon grains, by a strain of $\sim 5-7$. At higher strains the microstructure refines by the break-up of the ribbon grains into lower aspect ratio submicron grains. This occurs inhomogeneously and starts to develop locally in bands at strains as low as $\varepsilon_{\mathrm{vm}} \sim 4[8,10]$. The highstrain breakup and spheroidisation of lamellar HAB structures has been attributed to heterogeneity in plastic flow, diffuse shear banding, and dynamic recovery/recrystallisation $[8,10]$. Where severe deformation involves no net element shape change, due to a redundant strain, the development of the deformed state is less well understood, but grain refinement predominately occurs by deformation banding and shear banding $[8,9,10]$.

Here results are presented that use a selection of model $\mathrm{Al}$-alloys, processing routes, and die angles, to clarify in more detail some important aspects of the deformation structure development during ECAE processing. In particular, the role of the die's shear plane orientation in the formation of cell bands (or cell blocks) and shear bands, along with orientation splitting, at low strains is investigated, as well as if a steady state is ultimately achieved at ultra high strains. It is worth noting that in terms of developing a more complete understanding of the general development of deformation structures in metals ECAE offers certain advantages compared to plane strain deformation, as theoretically under ideal conditions there is one principal shear plane with an orientation defined by the die geometry, and this makes it easier to determine the crystallographic, or non-crystallographic, alignment of features such as cell bands and microshear bands.

\section{Experimental Conditions}

All the results presented were obtained by ECAE using a split die held in a hydraulic clamp, so that extrusion could be stopped partway through a cycle and samples extracted. Deformation was carried out at room temperature, on well lubricated $15 \mathrm{~mm}$ diameter by $100 \mathrm{~mm}$ billets, using a ram speed of $50 \mathrm{~mm} / \mathrm{min}$ and either a 90 or $120^{\circ}$ die $(=2 \phi)$, with only a small blend radius between the die channels. This restricted the deformation zone to a narrow fan of less than $2 \mathrm{~mm}$ in width about the theoretical shear plane [5]. Data from three materials is shown; a single phase $\mathrm{Al}-0.1 \% \mathrm{Mg}$, a fine 20 $\mathrm{nm} \mathrm{Al}{ }_{3} \mathrm{Sc}$ dispersoid containing $\left(\mathrm{V}_{\mathrm{f}}=0.004\right) \mathrm{Al}-\mathrm{Sc}$ alloy and AA8079, which contained coarse $\sim 2$ $\mu \mathrm{m} \mathrm{Al}_{13} \mathrm{Fe}_{4}$, particles $\left(\mathrm{V}_{\mathrm{f}}=0.025\right)$, deformed by route $\mathrm{A}$ and $\mathrm{B}_{\mathrm{C}}$. Most data shown below is for the Al- $0.1 \% \mathrm{Mg}$ alloy, except where comparisons are made to example data from the other materials. Full details of the materials and their pre-processing can be found in $[10,12,13]$. EBSD orientation maps were acquired from samples at different strain levels, using a high resolution FEG-SEM. Data analysis was carried out using VMap, an in-house software package. HABs were defined as having misorientations $\geq 15^{\circ}$ and low-angle boundaries (LABs) misorientations $<15^{\circ}$. A minimum misorientation cut-off of $1.5^{\circ}$ was normally used to eliminate excessive misorientation noise. In some maps "Kuwahara filter" orientation averaging of adjacent pixels was used to reduce noise levels at low misorientations, improving the orientation resolution to $\sim 0.5^{\circ}$.

\section{Mechanisms of Refinement}

Cell bands After the first pass of ECAE deformation the most characteristic feature of the fine scale deformation microstructure in dilute Al-alloys with a reasonable initial grain size $(>10 \mu \mathrm{m})$ are 
aligned dense dislocation walls (DDWs) $0.7-1.5 \mu \mathrm{m}$ in spacing (Fig 1). Similar features have been widely reported in rolling and ECAE [8-10, 14,15]. These structures have been termed 'cell blocks', where they have been suggested to represent volume elements operating on a similar set of slip systems, or are differentiated from their neighbouring blocks in terms of different local strains, and have been claimed to show preferential alignment with the active $\{111\}$ slip plane [15]. However, it has been shown recently that they are probably not crystallographically related and tend to align with the principle shear direction (e.g. $36^{\circ}$ to the rolling plane) [14]. In idealized ECAE deformation with a narrow deformation zone, the principal shear plane is theoretically the plane of intersection of the two die channels, and this allows a simple test of these two ideas, although pure shear does not generally occur in ECAE due to die friction and spreading of the deformation zone through an arc, which introduces other minor strain components [5,6]. Nevertheless, after 1 ECAE pass in all materials examined the DDWs in every grain were always found to be strongly aligned with the die shear plane across the centre of the billet, for both $90^{\circ}$ and $120^{\circ}$ dies, at $45^{\circ}$ and $60^{\circ}$ to ED respectively (Fig 1). Another set of cell bands was also seen within some grains aligned with the extrusion direction, which may reflect the presence of other strain components in imperfect ECAE shear. Slip plane trace analysis clearly showed that there was no preferential $\{111\}$ alignment, as can be seen from the example pole figure in Fig. 1c. The DDWs are typically only one cell wide, and contain very low angle transverse boundaries. Such structures are thus more accurately described as cell bands, as proposed by Humphreys and Hurley [14], and are formed by the coalescence of dislocation networks into sheets by climb onto planes where there is no out of plane shear. The average misorientation across the cell bands was $3-4^{\circ}$ for the $120^{\circ}$ die and $4-5^{\circ}$ for the $90^{\circ}$ die, which reflects the higher strain intensity of the lower die angle. No new HABs were formed at cell band boundaries, except where there was observed to be an underlying orientation gradient, either due to grain interactions, or deformation banding (see Fig. 4b). The cell band structure thus initially develops independently of orientations splitting, which is driven by crystal instability.
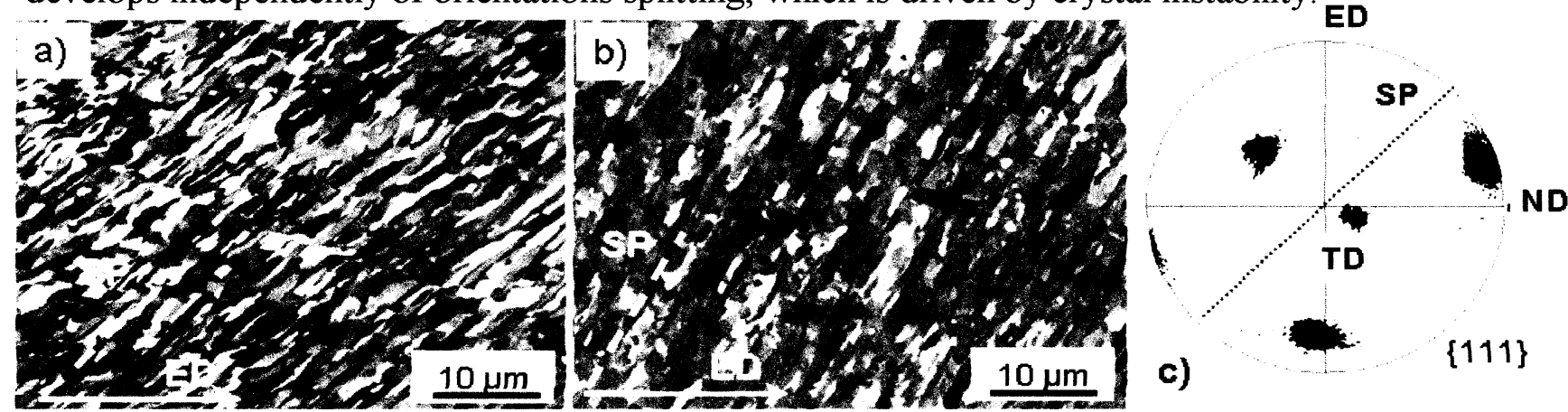

Fig. 1 Regular cell bands seen after a single ECAE pass with the $0.13 \% \mathrm{Mg}$ alloy through (a) 90 and (b) $120^{\circ}$ die. The cell bands are aligned closely with the dies shear plane (SP) in all grains and show no preferential alignment with $\{111\}$ slip planes; example $\{111\}$ pole figure in (c)

At low strains in rolling cell bands have been shown to initially maintain their $36^{\circ}$ angle to the rolling plane and thus rotate in the opposite direction to the material as it is compressed [14]. It was previously thought that a similar realignment may occur in ECAE deformation [12], but it has now been shown that the cell bands are permanent after the first pass and are rotated by microshear/shear banding in subsequent extrusions. At high strains, when the minimum grain fragment HAB spacing reduces to $\sim<5 \mu \mathrm{m}$ no regular cell bands are seen [8] and irregular subgrains are found, because when the crystal fragment size reduces below a certain level slip becomes less well defined with respect to the macroscopic shear stress, due to grain to grain interactions. A similar result has been reported for deformation structures in fine grained materials by Jazaeri and Humphreys [16]. 
Shear bands In the dilute alloys studied, microshear bands were not seen in the first pass. In the second pass with ECAE processing there is always a strain path change which depends on the die angle and processing route [7]. Except for in route $\mathrm{C}$, which represents a Bauschinger type reversal, this involves a rotation of the idealized shear plane and the activation of latent slip systems. For route A, the theoretical shear plane alternates by $\pi-\phi$ every cycle and should thus intercept the cell bands by $60^{\circ}$ or $90^{\circ}$, with the 120 and $90^{\circ}$ dies respectively. Such strain path changes are know to promote shear banding as the collapse of the lamellar DDWs barriers forming the cell bands, when subjected to an orthogonal shear, can lead to transient flow softening [17]

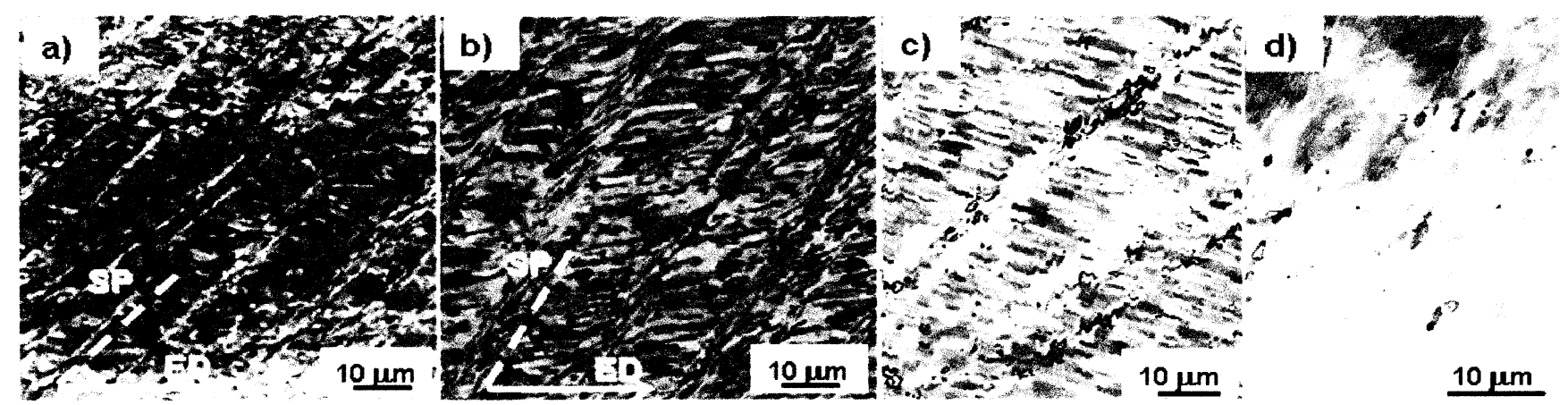

Fig. 2 Back scattered electron SEM images of microshear bands in the $0.13 \% \mathrm{Mg}$ alloy cutting through the cell band structure aligned closely with the die's shear plane, with in (a) 90 and (b) $120^{\circ}$ dies, and in (c) and (d) Kuwahara filtered, orientation enhanced, EBSD maps of the $0.13 \% \mathrm{Mg}$ alloy with a $90^{\circ}$ die (part way through deformation zone, $2^{\text {nd }}$ pass) and the $\mathrm{Al}-0.2 \% \mathrm{Sc}$ alloy with the $120^{\circ}$ die; all after pass 2 by route $\mathrm{A}$.

\begin{tabular}{|l|c|c|c|c|}
\hline & Angle to ED & Spacing & Width & Misorientation \\
\hline $\mathrm{Al}-0.1 \mathrm{Mg} 120^{\circ}$ die Route A & $60^{\circ}$ & $7-15 \mu \mathrm{m}$ & $1.1-10 \mu \mathrm{m}$ & $6.7-12.4^{\circ}\left(10.1^{\circ}\right) \mathrm{Max} \sim 24^{\circ}$ \\
\hline $\mathrm{Al}-0.1 \mathrm{Mg} 90^{\circ}$ die Route A & $45^{\circ}$ & $5-10 \mu \mathrm{m}$ & $0.8-8 \mu \mathrm{m}$ & $8.1-13.3^{\circ}\left(11.2^{\circ}\right)$ Max $\sim 30^{\circ}$ \\
\hline
\end{tabular}

Table 1 average statistical data for micro/shear bands formed in the $2^{\text {nd }}$ ECAE pass; the width is for a single band and the misorientations give the typical range, (average), and maximum recorded.

In Fig. 2 after the second ECAE pass microshear bands, only one cell wide, can now be seen cutting through the cell band structure aligned closely with the die's theoretical shear plane in both dies. Their average misorientation thickness and spacing are given in table 1 . The cell band substructure has rotated towards the extrusion direction $\sim 25^{\circ}$ and $15^{\circ}$ to ED for the $120^{\circ}$ and $90^{\circ}$ die respectively, but the alignment is spread and depends on the local shear band intensity. The cell band misorientations have remained at only $4-6^{\circ}$. Some microshear bands were seen in packets of two, to five, bands and extended across grain boundaries, although they did not generally propagate across the whole sample. It can thus be considered that there is a mixture of inter-granular microshear bands and microshear packets that are developing into trans-granular macroshear bands. In comparison in the same alloy single microshear bands are more commonly observed in rolling at similar strains, due to the lower intensity of the shear, and lack of an abrupt strain path change [14]. Substantial lattice rotations occur within the shear bands of $6-30^{\circ}$ (table 1) around TD towards the extrusion direction, which readily generates new HAB segments across their boundaries. The microshear bands were more regularly distributed and slightly higher in misorientation with the $90^{\circ}$ than the $120^{\circ}$ die, which reflects the higher strain intensity each pass. More intense and regular microshear bands were found within larger stable crystal volumes, that often coincided with when a $\{111\}$ crystallographic plane aligned with the dies shear plane, compared to areas subdivided by more closely spaced deformation bands, which reduces the intensity of intergranualar microshear bands by restricting the slip line length.

The microshear bands have medium misorientations and are permanent features of the deformation structure. Once formed, with route A, they undergo a rigid-body rotation towards the 
extrusion direction on subsequent cycles and their spacing is compressed $[8,10]$. This process, along with orientation splitting, is eventually responsible for the formation of lamellar boundary structures and the elongated "ribbon grains" observed at high strains $[8,10]$. At intermediate strains it causes a complex microstructure to develop by subsequent micro/shear bands kinking the rotated cell bands and earlier microshear bands. Micro/shear bands are also observed to form by route $\mathrm{B}_{\mathrm{c}}$, but their comparative intensity has not yet been quantified. However, they are less likely to form with processes where there is a direct Bauschinger strain path reversal [17], as typified by route $\mathrm{C}$. The importance of micro/shear bands to grain refinement in ECAE, at low strains, can be seen from the much higher rate of $\mathrm{HAB}$ area generation in a single phase alloy (Fig. 3a), relative to that in an Al$0.2 \% \mathrm{Sc}$ alloy, where their formation is suppressed because of slip homogenisaiton due to the presence of a high density of non-shearable fine particles (Fig. 2d) [12].
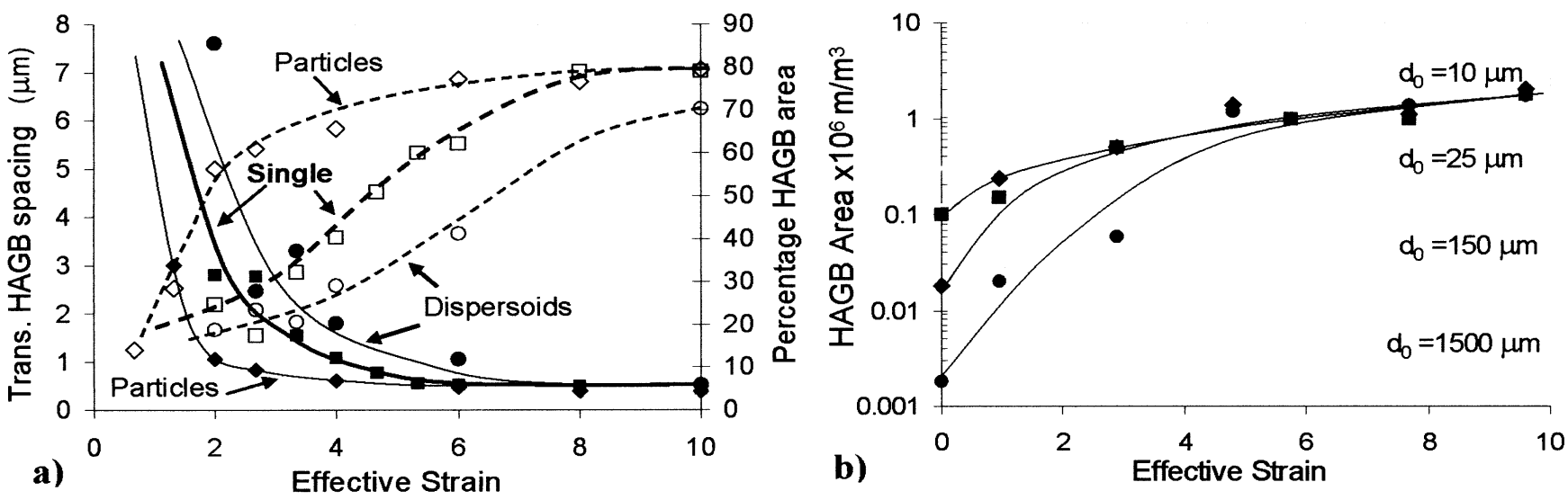

Fig. 3 (a) Comparison of the reduction in transverse HAB spacing (solid lines) and increase in HAB area (dashed lines), as a function of strain for the single phase (Al-0.13Mg) dispersoid (Al- $0.2 \mathrm{Sc}$ ) and coarse particle containing (8079) model alloys. (b) Measured boundary area, per unit volume, compared to that expected, due to the distortion of the original grains (dashed lines) for different initial grain sizes, in commercial purity $\mathrm{Al}$ deformed by ECAE [8].

Coarse macroscopic trans-billet shear banding can also be observed to occur in ECAE under unstable deformation conditions [5]. This particularly occurs in aluminium alloys when the material has been heavily work hardened and contains high levels of $\mathrm{Mg}$. Ultimately, this results in fracture of the billet, and can not thus be exploited to produce a homogeneous ultra-fine grain structure. Diffuse trans-granular shear bands at high strains have also been observed to contribute to the breakup of ribbon grains, produced by route $\mathrm{A}$, into ultrafine grains $[8,10]$.

Orientation splitting The formation of deformation bands in unstable grains, which subdivide into slab morphology volumes and rotate towards diverging end orientations, that define the deformation texture for a given deformation mode, is a well known phenomenon [18]. The pattern of deformation banding within a given grain appears to become established at relatively low strains, and occurs in ECAE during the first pass as a grain enters the dies deformation zone (Fig. 4a). Misorientations between each band typically alternate and increase with strain and the deformation bands are reduced in width and rotate towards ED with the original grain boundaries as the shear increases through the deformation zone (Fig. $4 \mathrm{~b} \& \mathrm{c}$ ). In the first pass the DDWs that make up the cell band boundaries remain aligned with the shear plane, or the extrusion direction, but where they coincide with steep orientation gradients, in narrow transition bands between the deformation bands, develop HAB segments, which then become continuous as the strain increases in subsequent passes. This can occur irregularly and form closely spaced parallel $\mathrm{HAB}$ segments, and occasionally submicron grain fragments within the transition bands in the process. Typically, two length scales of deformation 
banding were found (table 2), coarse primary deformation bands that have high misorientations of 30 - 55 (Fig. 4a) and a spacing of $\sim 20-30 \mu \mathrm{m}$ (after the first pass) and much finer secondary deformation bands, that can form within the primary bands in some grains, and have lower misoreintations $\left(\sim 10-20^{\circ}\right)$ and spacings as fine as $5 \mu \mathrm{m}$ (Fig. 4b). In subsequent passes with route A, these regions rapidly develop into local bands containing a high density of lamellar HABs. In the current work sufficient statistical data has not yet been obtained to correlate specific crystal orientations to grain stability in such regions. Theoretical analysis by Barnett and Montheillet [19] has suggested that, due to the material spin in simple shear, which results in no truly stable final deformation texture, orientation splitting is more significant than in other deformation modes, such as plane strain.

When comparing the behaviours seen with the two die angles, deformation banding appeared more well defined and widely spaced with the $120^{\circ}$, relative to the $90^{\circ}$, die. This could be simply because of the greater element distortion that results from the higher strain with the $90^{\circ}$ die, for the same number of cycles, but may e a result of differences in die friction effects.
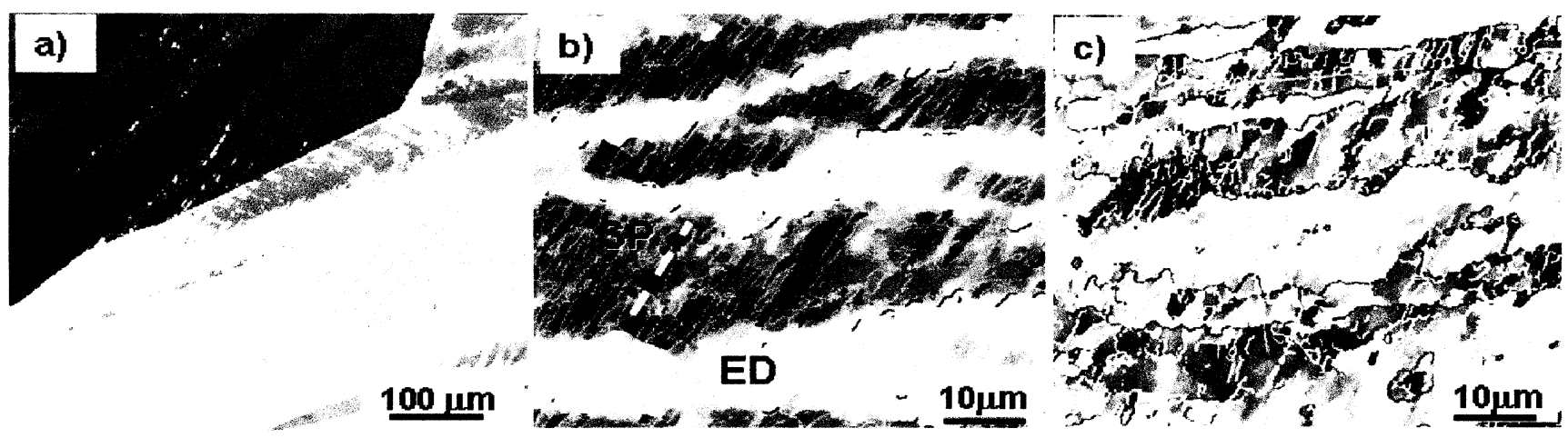

Fig. 4 Coarse primary (a) and (b) fine secondary deformation bands formed in the first pass in the $\mathrm{Al}-0.13 \mathrm{Mg}$ alloy with a $120^{\circ}$ die. In (c) cell bands have evolved HABs where they coincide with the secondary deformation band boundaries after the second pass.

\begin{tabular}{|c|c|c|c|c|c|c|}
\hline & \multicolumn{3}{|c|}{ Primary DBs } & \multicolumn{3}{c|}{ Secondary DBs } \\
\hline & Angle to ED & width & Mis-orientation & Angle to ED & width & Mis-orientation \\
\hline $90^{\circ}$ die Route A & $15-25^{\circ}$ & $20-35 \mu \mathrm{m}$ & $\sim 55^{\circ}$ & $0-10^{\circ}$ & $5-15 \mu \mathrm{m}$ & $10-25^{\circ}$ \\
\hline $120^{\circ}$ die Route A & $25-50^{\circ}$ & $20-35 \mu \mathrm{m}$ & $\sim 47^{\circ}$ & $0-10^{\circ}$ & $5-15 \mu \mathrm{m}$ & $7-20^{\circ}$ \\
\hline
\end{tabular}

Table 2. Mean misorientation and spacing of deformation bands seen with the 90 and $120^{\circ}$ die, for the $0.13 \% \mathrm{Mg}$ alloy after one ECAE pass.

Despite reorientation of the shear plane, on subsequent ECAE passes by route A the pattern of deformation banding formed in the first pass does not appear to change, (i.e. no more subdivision occurs), although the band width does reduce due to continued element distortion, and the misrorentation across bands increases resulting in the formation of continuous HABs at secondary bands (Fig.4c). Similarly, with route $B_{c}$ where there is no continuous element distortion, again the pattern of deformation banding developed after the first pass appears to largely remain during subsequent passes, unless the structure is destroyed by intense shear banding, such as that seen in high Mg content alloys. Crystal plasticity simulations have shown similar results, in that the pattern of orientation subdivision is generally determined at relatively low strains [11].

Cell bands can also develop HABs in regions near grain boundary surfaces and triple points, in the original grain structure, due to high local orientation gradients resulting from grain-grain interactions [8]. New HABs can also be promoted by orientation gradients associated with coarse second phase particles, within their deformation zones and through particle stimulated deformation bands. This 
greatly increases the rate of grain refinement and reduces the strain required to produce an ultra-fine grain structure [13], as can be seen from Fig. 3a.

Importance of geometric boundary compression In most conventional deformation processes continuous distortion of a material element occurs. This leads to an increase in grain boundary area simply due to the geometric shape change imposed on a grain [18]. In ECAE deformation continuous element distortion does take place by route $\mathrm{A}$ and $\mathrm{B}_{\mathrm{A}}$, but not by Route $\mathrm{B}_{\mathrm{c}}$ or $\mathrm{C}$. The grain subdivision mechanisms of orientation splitting, and repeated micro/shear banding at low strains and transgranular shear banding at high strains, on alternate shear planes, are therefore primarily responsible for grain refinement by Route $B_{C}$. With route $A$, as well as orientation splitting and shear banding resulting in grain subdivision there is also an increase in HAB area due to the geometric requirements of shear associated with the development of a fibrous deformation structure, which results in a lamellar HAB structure at strains grater than $\sim 3-4$. At higher strains of $\sim 5-7$ the lamellar boundary spacing approaches the subgrain size and ribbon grains are formed which subsequently breakup and reduce in aspect ratio to form submicron grains at ultra-high strains $[8,10]$. In Fig. $3 b$ the measured increase in $\mathrm{HAB}$ area with strain, for different original grain sizes, is compared to that calculated from the geometric increase in HAB area, based on the theoretically distortion of grains that deform homogenously. From Fig. $3 \mathrm{~b}$ it can be seen that at low strains the geometric increase in $\mathrm{HAB}$ area becomes extremely important when the initial grain size reduces below $\sim 25 \mu \mathrm{m}$, and at high strains all the data converges with the predicted behaviour for an initial grain size of $10 \mu \mathrm{m}$. Jazaeri and Humphreys have shown that in rolling all new HAB area can be attributed to the geometric increase in boundary area for grain sizes below $\sim 10-15 \mu \mathrm{m}$ [20]. However, for smaller initial grain sizes the reduction in HAB spacing falls below that expected from the geometrical requirements of strain, which suggests a minimum HAB spacing is approached that is controlled by dynamic recovery. An effective limit to grain refinement is also observed in ECAE processing, when the grain size converges with the subgrain size, as will be shown below.

Severely Deformed Microstructures With deformation paths that do not involve a net element shape change, such as route $B_{C}$, if deformation occurs homogeneously there is no geometric requirement for a compression of the boundary spacing, or increase in HAB area with strain. However, grain subdivision processes will still result in grain refinement and a geometric increase in boundary area can still occur locally if deformation occurs heterogeneously within intense macroshear bands. Thus, at ultra high strains by ECAE, both routes $\mathrm{A}$ and $\mathrm{B}_{\mathrm{C}}$ can produce ultra-fine grained materials, but result in distinctively different deformation structures, examples of which are given in Fig. 5. Materials produced by route $\mathrm{A}$, with continuous element distortion, (Fig. 5a, b) have fibrous ultra-fine grain structures, which tend to be quite homogeneous in the transverse direction, but have a lower average boundary misorientation in the grain elongation direction and still contain surviving long ribbon grain fragments. With route $\mathrm{B}_{\mathrm{C}}$, shear banding on alternate planes and the lack of an overall compression of the structure with strain, results in a more chaotic microstructure, which contains lower misorientation subgrain islands within a matrix of ultra-fine grains (Fig. 5c). These submicron grains are frequently finer in scale and elongated within shear bands created in the last pass.

If a mechanism of grain subdivision, such as micro/shear banding is suppressed by the inclusion of high densities of dispersoids, which are frequently used in superplastic alloys [12], both route $A$ and route $B_{C}$ result in more heterogeneous structures. However, route $B_{C}$ is much more significantly affected due to the lack of any general geometric boundary extension. With route A larger unrefined fibrous grains are retained (Fig. 5b), which correspond to volumes with more stable orientations, which are no longer subdivided by micro/shear banding [12]. But, with route $\mathrm{B}_{\mathrm{C}}$, due to the suppression of shear banding, the material can no longer be described as submicron grained and 
contains only $\sim 45 \%$ HABs (Fig. 5 d). In contrast, materials produced by any deformation route can be made more homogenous by including coarse second phase particles, which encourages matrix orientation divergence at low strains and breaks up lamellar HAB structures at high strains [13].

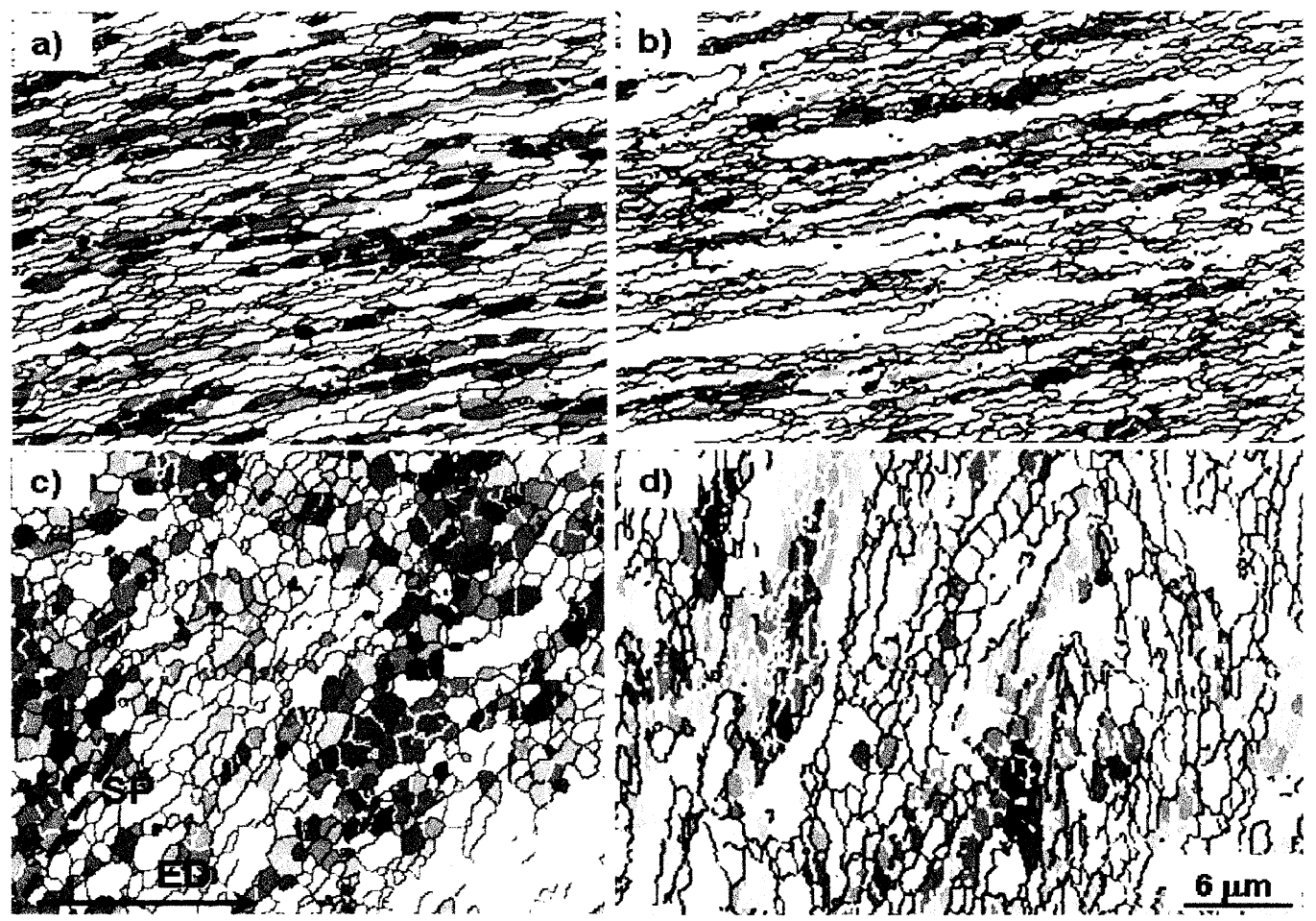

Fig. 5 Ultra-high strain deformation structures in (a) an $\mathrm{Al}-0.13 \mathrm{Mg}$ alloy, (b) $\mathrm{Al} 0.2 \% \mathrm{Sc}$ alloy using route $\mathrm{A}$, (b) and in (c) $\mathrm{Al}-0.13 \mathrm{Mg}$ and (d) $\mathrm{Al} 0.2 \% \mathrm{Sc}$ with route $\mathrm{B}_{\mathrm{c}} ; 15 \mathrm{ECAE}$ passes $\left(\varepsilon_{\mathrm{eff}} \sim 10\right)$ with a $120^{\circ}$ die.

Steady state and dynamic recovery If the deformation conditions are maintained constant, ultimately a steady state must be approached in severe deformation where there is no further grain refinement. An example of this behaviour can be seen in Fig. $6 \mathrm{a}$, where statistical data obtained by EBSD shows little significant difference in the fraction of $\mathrm{HAB}$ area, and a negligible reduction in grain width, in the strain range $\sim 8-17$, using route A. At this stage the grain width has converged with the cell size. There is, however, still a noticeable reduction in average grain length. This occurs due to the breakup of the final remaining long fibrous ribbon grain fragments, resulting in an increase in homogeneity of the material. Due to the geometric requirements of the imposed shear, the grain width should be reducing with strain at a much higher rate, although this is less significant than in plane strain where a similar limiting grain width has been observed by Jazaeri et al. [20,21]. This is illustrated in Fig. 6a where the theoretical grain width is geometrically required by shear to reduce by the order of $0.1-0.02 \mu \mathrm{m}$ per extrusion cycle in this strain range.

If a constant grain width is maintained dynamically, with a ram speed of $50 \mathrm{~mm} / \mathrm{min}$ and deformation zone width of $\sim 2 \mathrm{~mm}$, this corresponds to a boundary migration velocity of $\sim 0.01-$ $0.04 \mu \mathrm{m} \mathrm{s}^{-1}$. The conventional thermally activated migration rate of a boundary is given by [18]:

$$
\mathrm{V}=\mathrm{M}_{\mathrm{o}} \exp (-\mathrm{Q} / \mathrm{RT}) \mathrm{P}
$$

If the average driving force for boundary migration, $P$, is equivalent to $3 \gamma / \mathrm{d}$, using typical measured values of $\gamma=0.3 \mathrm{Jm}^{-2}$, a grain size $\mathrm{d} \sim 0.7 \mu \mathrm{m}, \mathrm{M}_{0} \sim 0.13 \mathrm{~m}^{4} \mathrm{~J}^{-1} \mathrm{~s}^{-1}$, and an activation energy of $130 \mathrm{~kJ}$ $\mathrm{mol}^{-1}[21]$, this gives, assuming a deformation temperature due to plastic work of $\sim 50^{\circ} \mathrm{C}$, a velocity of $\sim 1 \times 10^{-10} \mu \mathrm{m} \mathrm{s}^{-1}$, which is too low by a factor of $\sim 10^{8}$ to maintain a constant grain width. However estimated, unrealistic values of $\mathrm{P}$ would be required to greatly increase $\mathrm{V}$. In comparison an effective activation energy and a value of $\sim 80 \mathrm{~kJ} \mathrm{~mol}^{-1}$ will result in the required migration rate. 
Similar values of $\mathrm{Q}$ have been reported for static grain growth at low temperatures in severely deformed alloys, using TEM measurements, but these results are generally confusing as they can also be attributed to misinterpretation resulting from the heterogeneous nature of the deformation structures [22]. However, overall the data suggests that a limiting grain size is achieved due to dynamic grain boundary migration occurring at a far higher rate than for conventional static annealing. This could result from the interaction of dislocations with HABs, a higher vacancy concentration, and higher local driving pressures due to non-equilibrium boundary configurations.

It is also apparent that limited dynamic boundary migration could contribute to the grain refinement process at high strains once the HAB spacing in local bands reduces to the subgrain size and, for example, facilitate some spheroidisation and the break up of thin ribbon grains in a manner similar to that observed during static annealing of lamellar HAB structures at higher temperatures [22]. Simulations have shown this occurs because even low angle transverse boundaries exert a large resolved surface tension at nodal points in lamellar boundary structures. A strongly developing texture can also reduce the $\mathrm{HAB}$ density during deformation, but the texture is generally relatively weak in ECAE [10]. Further grain refinement can thus only be achieved by increasing the ZenerHollomon parameter. The remarkable effect of reducing the deformation temperature is illustrated in Fig. $6 \mathrm{~b}$, where the $\mathrm{Al}-0.13 \mathrm{Mg}$ alloy after processing by ECAE at $20^{\circ} \mathrm{C}$ temperature to $\varepsilon_{\text {eff }}=10$ (Fig. 5a) has been subsequently deformed in plane strain compression in liquid nitrogen to a further strain of $\varepsilon_{\text {true }}=2$, resulting in thin ribbon grains of $\sim 100 \mathrm{~nm}$ in width.
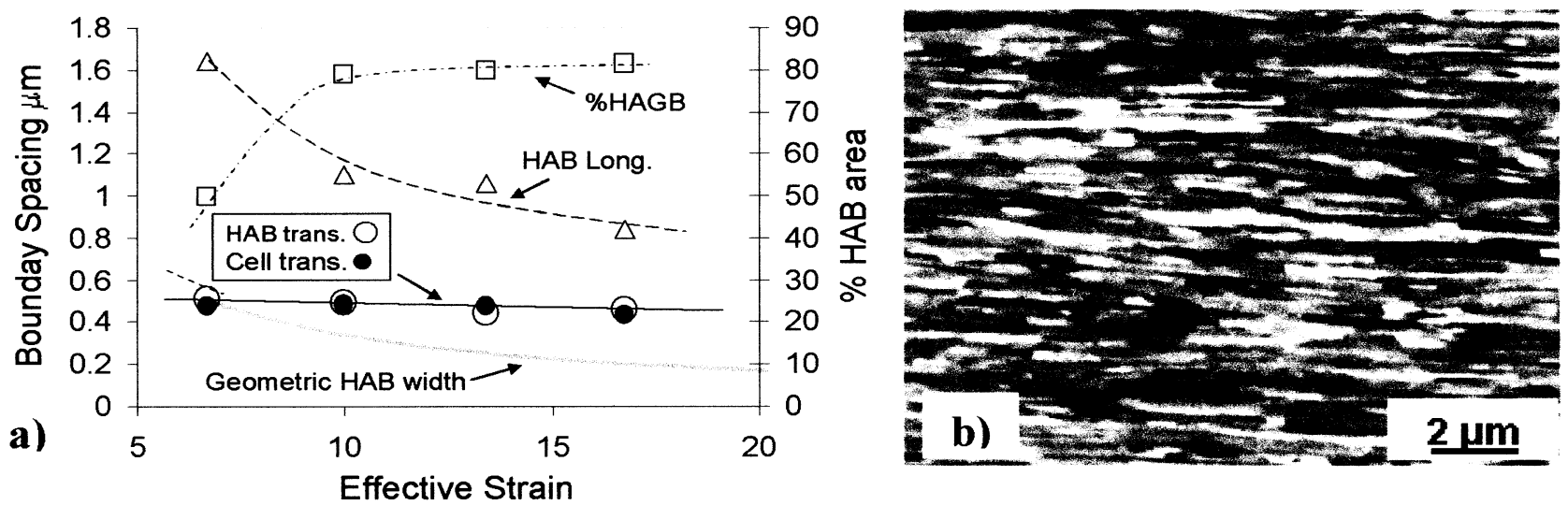

Fig. 6 (a) Statistical data obtained by ECAE showing the fraction of HAB area, average longitudinal and transverse $\mathrm{HAB}$ spacing, as well as transverse cell width, in the strain range $\sim 8-17$, using route $\mathrm{A}$ with the $\mathrm{Al}-0.13 \mathrm{Mg}$ alloy and a $120^{\circ}$ die. (b) The same alloy deformed in plane strain compression at $-195{ }^{\circ} \mathrm{C}$ to a further strain of $\varepsilon_{\text {true }}=2$, after processing by ECAE at room temperature to a strain of $\varepsilon_{\text {eff }}=10$.

\section{Summary}

Grain refinement in high stacking fault energy FCC metals during severe deformation processes, like ECAE, occurs predominantly by orientation splitting, micro and macroshear banding, and the geometric requirements for high angle boundary area to increase with strain. The deformation structure evolution is strongly affected by the processing route, die geometry, and material parameters. Both cell bands and microshear bands show alignment with the dies shear plane and micro/shear bands are promoted by changes in the shear plane orientation each extrusion cycle. The geometrically required increase in boundary area and compression in boundary spacing with strain is an important aspect of the formation of fibrous ultra-fine grain structures with route A, and increases in significance with smaller initial grain sizes. The introduction of fine non-shearable second phase particles results in a reduction in the rate of grain refinement by the homogenisation of slip which results, when combined with processing routes that involve redundant strains (e.g. Route $\mathrm{B}_{\mathrm{C}}$ ), in 
materials that predominantly contain subgrains. In contrast, coarse second phase particles accelerate the rate of grain refinement and increase homogeneity of the final grain structure. At high strains a steady state is achieved, due to dynamic boundary migration occurring at far higher rate than under static conditions, resulting in a constant minimum grain size. Dynamic boundary migration also contributes to the grain refinement process at high strains when the HAB spacing approaches the subgrain size. Further grain refinement can thus only be achieved by increasing the Zener-Hollomon parameter.

\section{Acknowledgements}

The authors are grateful to the continued support and insight of Professor John Humphreys over a large number of years and for funding from University of Manchester EPSRC Light Alloys Portfolio Partnership (EP/D029201/1).

\section{References}

[1] R.Z. Valiev, R.K. Islamgaliev and I.V. Alexandrov: Prog. Mat. Sci. Vol. 45 (2000), p. 103.

[2] Y.M. Wang and E. Ma: Acta Mater. Vol. 52 (2004), p. 1699.

[3] P.J. Apps, C.P. Heason and P.B. Prangnell: Mat. Sci. Forum Vol. 447-448 (2004), p. 423.

[4] Y. Huang: UK patent ap. No. GB 0400142.6 (06/01/04).

[5] V. M. Segal: Mat. Sci. Eng. Vol. A271 (1999), p. 322

[6] J.R. Bowen, A. Gholinia, S.M. Roberts, P.B. Prangnell: Mat. Sci. Eng. Vol. A287 (2000), p. 87.

[7] L. Dupy, and E.F. Rauch: Mater. Sci Eng. Vol. A337 (2002), p. 241.

[8] P.B. Prangnell, J.R. Bowen, and A. Gholinia: 22nd Risø Int. Symp. on Science of Metastable and Nanocrystalline alloys, A.R. Dinesen et al. (Eds.), Roskilde, Denmark, 2001, p. 105.

[9] M. Berta, P. J. Apps and P. B. Prangnell: Mat Sci Eng. A. Vol. 410-411 (2005), p. 381.

[10] P.B. Prangnell, J.R. Bowen and P.J. Apps: Mater. Sci. Eng. A Vol. 375-377 (2004), p. 178.

[11] P.D Wu, Y. Huang, and D.J. Lloyd: Scripta Mater. Vol. 54 (2006), p. 2107.

[12] P.J. Apps, M. Berta, and P.B. Prangnell: Acta Mater. Vol. 53 (2004), p. 499.

[13] P.J. Apps, J.R. Bowen and P.B. Prangnell: Acta Mater. Vol. 51 (2003), p. 2811.

[14] P.J. Hurley, and F.J. Humphreys: Acta Mater. Vol. 51 (2003), p. 1087.

[15] B. Bay, N. Hansen, D.A. Hughes, D. Kuhlmann-Wilsdorf: Acta Mater. Vol. 40 (1992), p. 205.

[16] H. Jazaeri and F.J. Humphreys: Mat. Sci. Forum. Vol. 467-470 (2004), p. 63.

[17] E.F. Rauch: Solid State Phenomena Vol. 23-24 (1992), p. 317.

[18] F.J. Humphreys and M. Hatherly: Recrystallization and Annealing Phenomena (Oxford Pergamon 1995).

[19] M.R. Barnett and F. Montheillet: Acta Mater. Vol. 50 (2002), p. 2285

[20] H. Jazaeri and F.J. Humphreys: Acta Mater. Vol. 52(2004), p. 3239.

[21] H. Jazaeri and F. J. Humphreys, Mat. Sci. Forum. Vol. 519-521, (2006), p. 153.

[22] P.B. Prangnell, M. Berta, P.J. Apps, and P.S. Bate: 2nd Int. Conf. On Recrystallisation and Grain Growth, ed Bacroix et al., August, Annecy, France, (2004), p 1261. 